\title{
Aggregated Evaluation of Industrial Safety Level of a Dangerous Production Object Based on Knowledge Technologies
}

\author{
Elizaveta A. Aslamova \\ Irkutsk State University of Railway Transport \\ Irkutsk, Russia \\ liza.Ocean@mail.ru
}

\author{
Vera S. Aslamova \\ Irkutsk State University of Railway Transport \\ Irkutsk, Russia \\ aslamovav@yandex.ru
}

\begin{abstract}
The work presents the knowledge base of the expert system of the aggregate assessment of the level of industrial safety at a hazardous production facility, based on the use of the logico-axiological approach. The fundamental hypothesis: the reduction in production safety is due to the presence of "NE-factors": poor implementation of organizational measures, improper working conditions, inadequate personal protective equipment and so on. Failure to take measures to provide protection against industrial accidents leads to a reduction in the level of industrial safety. According to the approach used, the influence of "NOT-factors" on the level of "non-safety" of production is formalized by products of the type: $\neg \mathbf{A} \rightarrow \neg \mathbf{B}$.
\end{abstract}

Keywords-aggregated estimation; knowledge base; attached conclusion; expert system; industrial safety; factor classes; dangerous production facility.

\section{CLASSIFICATION OF METHODS OF ESTIMATION OF THE LEVEL OF PRODUCTION SAFETY}

For assessing the level of industrial safety of RAs, the probabilistic-statistical approach and risk analysis are mainly used on the basis of calculation of such indicators as [1-3]:

- accidents at hazardous production facilities (GRE). At the same time, neither the nature of the accident nor its consequences were taken into account. These indicators are not able to adequately reflect the real picture, since the number of accidents ranges from 100 to 200 per year, and the total number of supervised GCOs is 110,000 ;

- cases of fatal injuries;

- sectoral specialization of the enterprise (the ratio of the number of injured workers to the volume of extracted products). In the main pipelines, the accident rate is related to the length of the networks. The disadvantage of this approach is a narrow focus of activity and inefficiencies in assessing the performance of small enterprises with no injuries;

- the magnitude of damage to the consequences of accidents and incidents. The disadvantage is the impossibility or laboriousness of determining a number of indices of the damage;

- the results of supervisory and supervisory activities: the number of inspections, violations, disciplinary actions against persons who committed violations, measures aimed at improving the level of industrial safety; speed of response to identified violations; skill level of the staff. The disadvantage is the subjectivity of evaluation and the great dependence on the thoroughness of carrying out activities in the field of industrial safety.

The authors of [4] put forward the hypothesis that safety indicators are related to the operational characteristics of a manufacturing enterprise.

In work [5], studies on the use of the Six Sigma method for determining the causes of accidents and improving the level of safety in the company are described. The following six-sigma tools are used: definition, measurement, analysis. To determine the causes of accidents, statistics and interviews with company employees were used. After analyzing the main causes of accidents (lack of professional skills and work experience, human factor), a plan was proposed to reduce the risk of accidents and control the level of safety.

The article [6] discusses the relationship between the lean manufacturing method and industrial safety management. It is shown that effective tools for ensuring industrial safety are the use of $6 \mathrm{~S}$ process $=5 \mathrm{~S}$ Process (Sort, Set in order, Sweep, companies that fail to utilize a technical approach to Standardize, Sustain) + Safety.

The article [7] compares the quality assessments of OSH management systems in Iran, non-certified and certified by OHSAS 18001: 2007 "Health and Safety Management System". It was revealed that occupational safety and health are certified. companies have a higher level of security.

\section{Methodology of the LOGiCO-AXIOLOGiCAl EVAluation OF THE SAFETY LEVEL OF THE GRO}

Despite a large number of works in the field of risk assessment, the problem of quantifying the level of industrial safety of the GCO has not yet been solved [8]. Therefore, logico-axiological evaluation of the quality of technical systems is of great interest. The methodology of logicoaxiological evaluation of the quality of technical systems was first presented in $[9,10]$. The possibilities of this approach are described in more detail in $[10,11]$. We will apply this approach to assess the level of industrial safety at the GCO. 
Hypothesis: accident-free operation of any production system, including the GCO, requires the joint action of all its subsystems and the damage to the state of a subsystem entails damage to the state of the system as a whole. Formally, this is described by a set of fuzzy cause-effect relationships (products) of the form: "If He-A, then He-B", where B refers to the component being evaluated (safety-level assessment system), and $\mathrm{A}$ - to one of the subcomponents that form it directly (subsystems or functional elements). The states of each of the components are expressed by numbers from the interval $[0,1]$. In this case, 1 means the full functioning of the component, and 0 means its loss. In fact, we are talking about the fuzzy truth of judgments "Component A functions fully" and "Component B functions fully". Unclear formalizes the degree of influence of damage to component $\mathrm{A}$, on its component $\mathrm{B}$, which is expressed by a number from the interval $[0,1]$. That is, it is about the truth of the cause-effect relationship "Damage to functioning A entails damage to the functioning of $\mathrm{B}$ ". The truth of this connection is called the value of $\mathrm{A}$ for $\mathrm{B}$.

The system of ensuring accident-free operation and industrial safety at the GCO is described by the corresponding production system, an example of which will be presented below. The estimation itself looks like a fuzzy connected conclusion based on knowledge (BZ), consisting of these products and is implemented on the basis of technology of expert systems (knowledge technologies). The estimation looks like a fuzzy connected conclusion based on knowledge (BZ), consisting of products: $\neg A \rightarrow \neg B$. The conclusion is realized on the basis of technology of expert systems. Output of a straight line. The starting facts are assessments of the state of the initial functional elements of the production safety system, and the result is an aggregate assessment of the state of the system as a whole.

Table 1 provides a list of the main factors that lead to accidents and reduce the level of industrial safety of the GRO on the example of OAO Gazpromregiongaz according to data for 2005-2009. [4, 6]. The figure shows a conceptual model of the system of ensuring the safety of GRO in the form of a tree of classes of factors that ensure industrial security.

TABLE I. THE MAIN FACTORS AFFECTING THE LEVEL OF INDUSTRIAL SAFETY OF THE GRO

\begin{tabular}{|l|c|}
\hline \multicolumn{1}{|c|}{ Factor name } & Failures by factor,\% \\
\hline process safety assurance & 17 \\
\hline technical condition of the GRO & 22 \\
\hline timeliness of routine maintenance & 21 \\
\hline level of organization of work & 13 \\
\hline $\begin{array}{l}\text { qualification and knowledge of personnel of } \\
\text { NTD }\end{array}$ & 15 \\
\hline compliance with Rostechnadzor regulations & 12 \\
\hline
\end{tabular}

a. The main factors affecting the level of industrial safety of the GRO

The figure shows a conceptual model of the system of ensuring the safety of GRO in the form of a tree of classes of factors that ensure industrial security.

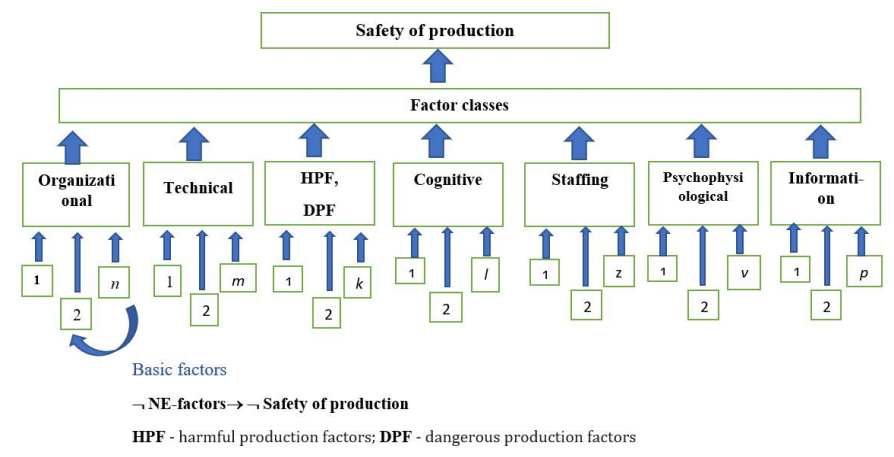

Fig. 1. Conceptual model of the production safety system.

Form the entire chain of causes of accidents and group it by class.

Not the security of the organizational class is determined by the following NOT factors: lack of or poor quality of conduct: training and briefing, project work, instructions on labor safety; unsatisfactory organization of workplaces; on-the-culmination of the technological process, the regime of work and leisure, etc. The shortage of measures leads to not the security of the organizational class.

Not the security of the technical class is conditioned by the following NOT factors: non-reliability and accidents of equipment, devices, collective and individual protective equipment; lack of mechanization and automation of technological processes; non-ergonomics of workplaces; constructive shortcomings and imperfection of equipment; absence or malfunction of fencing, safety, blocking, signaling and other devices; imperfection of the technological process; failure to comply with the timing of preventive maintenance; lack of adequate personal protective equipment, etc.

NOT safety of hazardous and harmful production factors (OPF and VFF) is determined by the following NOT factors: unfavorable parameters of the production microclimate, lighting, increased noise and vibration; monotonous conditions of work; high concentration of harmful substances; the presence of electromagnetic, electric and electrostatic fields, the severity and strain of the labor, etc.

NOT security of the cognitive class is determined by the following NOT factors: non-knowledge and misunderstanding by the staff of their role in the technological chain, technical regulations of production; normative and legal acts on industrial safety; rules for the use of personal protective equipment; rules of behavior in abnormal situations; causes and consequences of accidents, etc.

Not the safety of the psychophysiological class is determined by the following NOT factors: increased fatigue, fatigue, low concentration of attention, slow reaction speed, non-stress-resistance, lack of discipline, irresponsibility, incompatibility of the psychological characteristics of the employee with the conditions of work performed, etc.

Not the safety of the personnel class is determined by the following NOT factors: lack of professional training, short work experience, incompatibility of the employee with the position, etc. 
Not the security of the information class is determined by the following NOT factors: the absence of warning posters, safety signs, markings, fences of dangerous zones, etc.

It is easy to see that in both cases the emergence and development of an unfavorable situation is due to "NONfactors": shortcomings, incomplete / poor implementation of relevant measures, low staff readiness, lack of suitable working conditions, etc., which are naturally formalized within the framework of the proposed approach. At the same time, the concept of value allows us to take into account the significance of each factor for the corresponding subsystem, and the approach itself is to declare certain factors key, which can devalue the entire system as a whole. Taking any of these representations as a basis, we obtain the following system of evaluated facts and products (we will use the first approach on the basis of factor classes).

TABLE II. KNOWLEDGE BASE

\begin{tabular}{|c|c|}
\hline $\begin{array}{l}\text { Class } \\
\text { name }\end{array}$ & Basic factors \\
\hline \multirow{5}{*}{$\begin{array}{l}\text { Organiz } \\
\text { ational }\end{array}$} & $\begin{array}{l}\text { requirements for labor protection and industrial safety are } \\
\text { fulfilled }\end{array}$ \\
\hline & $\begin{array}{l}\text { training and instruction of personnel are conducted in a } \\
\text { timely and qualitative manner }\end{array}$ \\
\hline & there is a project of work, briefings on labor protection \\
\hline & satisfactory job organization \\
\hline & mode of work and rest is observed \\
\hline \multirow{6}{*}{$\begin{array}{l}\text { Technic } \\
\text { al }\end{array}$} & equipment and adaptations are good \\
\hline & there are means of mechanization, automation \\
\hline & there are no design flaws and imperfect equipment \\
\hline & $\begin{array}{l}\text { there are and are non-defective enclosing, safety, blocking } \\
\text { and other devices }\end{array}$ \\
\hline & the terms of preventive maintenance are observed \\
\hline & ergonomics of jobs is satisfactory \\
\hline \multirow{3}{*}{$\begin{array}{l}\text { Harmful } \\
\text { and } \\
\text { dangero } \\
\text { us } \\
\text { producti } \\
\text { on } \\
\text { factors }\end{array}$} & $\begin{array}{l}\text { adverse parameters of the industrial microclimate, lighting, } \\
\text { noise, vibration and others are normal }\end{array}$ \\
\hline & absence of monotonous working conditions \\
\hline & he intensity and severity of the work process is normal \\
\hline \multirow{3}{*}{$\begin{array}{l}\text { Psychop } \\
\text { hysiolo } \\
\text { gical }\end{array}$} & $\begin{array}{l}\text { fatigue, mindfulness, reaction speed and stress resistance of } \\
\text { employees are normal }\end{array}$ \\
\hline & $\begin{array}{l}\text { psychophysical characteristics of employees meet the } \\
\text { conditions of the work performed }\end{array}$ \\
\hline & disciplined and responsible attitude to the duties performed \\
\hline \multirow{3}{*}{ Staffing } & workers are professionally trained \\
\hline & necessary length of service in harmful working conditions \\
\hline & compliance of the employee with the position held, etc. \\
\hline \multirow{4}{*}{$\begin{array}{l}\text { Cogniti } \\
\text { ve }\end{array}$} & $\begin{array}{l}\text { knowledge and understanding of its role in the technological } \\
\text { chain }\end{array}$ \\
\hline & $\begin{array}{l}\text { knowledge of technical regulations of production, } \\
\text { requirements and regulations on industrial safety }\end{array}$ \\
\hline & $\begin{array}{l}\text { knowledge of the rules for the use of personal protective } \\
\text { equipment and behavior in abnormal situations }\end{array}$ \\
\hline & $\begin{array}{l}\text { knowledge and understanding by staff of the causes and } \\
\text { consequences of accidents, etc. }\end{array}$ \\
\hline
\end{tabular}

\begin{tabular}{|l|l|}
\hline $\begin{array}{c}\text { Class } \\
\text { name }\end{array}$ & \multicolumn{1}{c|}{ Basic factors } \\
\hline \multirow{2}{*}{$\begin{array}{l}\text { Informa } \\
\text { tion }\end{array}$} & availability of warning posters, safety signs \\
\cline { 2 - 2 } & presence of markings and fencing of hazardous areas, etc. \\
\hline
\end{tabular}

\section{TOTAL AGgREGATE OUTPUT}

Industrial safety in GCO is provided and the system of personnel protection against dangerous factors and injuries is normal. Using the listed facts, we will compose them into the corresponding products. Produktsiya is a construction of the form: IF A $\rightarrow$ B.

NOT refinement of the underlying factor, entails NOT updating the corresponding class of factors. Here are just a few products for the basic factors of the organizational class:

- NOT (it is true that) - "training and instruction of personnel is conducted in a timely and qualitative manner" $\rightarrow$ Not (it is true that) "organizational arrangements are provided";

- NOT "there is a project of work, briefings on labor protection" $\rightarrow$ Not "organizational arrangements are provided";

- NOT "the workplaces are organized satisfactorily" $\rightarrow$ Non-"organizational arrangements are provided";

- NOT «the technological process is observed» $\rightarrow$ Non"organizational measures are provided";

- NOT "the discipline of labor is high" $\rightarrow$ Non"organizational arrangements are provided";

- NOT "the mode of work and rest is observed" $\rightarrow$ Non"organizational arrangements are provided";

- NOT "there are and are properly used personal protective equipment" $\rightarrow$ Non-organizational arrangements are provided ".Maintaining the Integrity of the Specifications.

For other groups of product factors are constructed similarly. Aggregating products are needed:

- NOT "organizational arrangements are provided" $\rightarrow$ Not "industrial safety is ensured";

- NOT "technical conditions are normal" $\rightarrow$ Not "industrial security";

- NOT "OPF and VFF in norm" $\rightarrow$ Not "industrial safety is ensured";

- NOT "psychophysiological condition of employees in the norm" $\rightarrow$ Not "industrial safety is ensured".

- NOT "professional preparedness of employees in the norm" $\rightarrow$ Not "industrial safety is ensured";

- NOT "workers have the necessary knowledge of occupational safety and industrial safety" $\rightarrow$ Not "industrial safety is ensured";

- NOT "hazard information signs are available" $\rightarrow$ Not "industrial safety is ensured". 


\section{LOGICAL OUTPUT OF THE UNIT}

The truth of the initial facts is estimated on the scale $[0,1]$, or, more conveniently, on an integer scale of $0 \div 100$. The truth of the intermediate (here this aggregating facts) - according to the rule of modus ponens, taking into account the calculation of the truth of the conclusion on the basis of the truth of the premises:

$$
\neg \mathrm{A}, \neg \mathrm{A} \rightarrow \neg \mathrm{B} \vdash \neg \mathrm{B}: \mid \neg \mathrm{B}\|=\| \neg \mathrm{A}\|\cdot\| \neg \mathrm{A} \rightarrow \neg \mathrm{B} \| .
$$

Here the symbol $f$ separates the parcels from the conclusion; after the colon is indicated the method of calculating the truth of the conclusion; $\|\neg \mathrm{A}\|$ - the truth of the negation of the fact $\mathrm{A},\|\neg \mathrm{A} \rightarrow \neg \mathrm{B}\|$ - the truth of the implication "If NOT ..., then NOT ..." (A value for B).

Aggregation is carried out using the rule of association of evidence, which, taking into account the probabilistic nature of events, it is advisable to take in the form:

$$
\|\neg \mathrm{B}\|=\|\neg \mathrm{B}\| 1+\|\neg \mathrm{B}\| 2-\|\neg \mathrm{B}\| 1 \cdot\|\neg \mathrm{B}\| 2 ;
$$

$\|\neg B\| 1$ и $\|\neg B\| 2-$ the values of the truth of the negation $B$, obtained by different output chains.

The required aggregate value is: $\|\mathrm{B}\|=1-\|\neg \mathrm{B}\|$.

The risk, only this will not be "probabilistic", but some kind of "fuzzy" risk, can be calculated as the product of the aggregate evaluation of the system for damage from the occurrence of an accident.

Consider the construction of a logical inference by an example. Let the fact $\mathrm{A} 1=$ "organizational arrangements are provided". The auditor's assessment of the degree of influence of the organizational factor class on safety is "good" $(0.8)$. A2 $=$ "technical conditions are normal", the auditor's assessment of the degree of influence of the technical factor class on safety is "different" (0.9).

$\mathrm{B}=$ "industrial safety of the GRO is ensured". According to expert estimates, the price $\mathrm{A} 1$ for $\mathrm{B}=0.4$; the value of $\mathrm{A} 2$ for $\mathrm{B}=0.5$. $=0,08$.

Output step 1: $\neg \mathrm{A} 1, \neg \mathrm{A} 1 \rightarrow \neg \mathrm{B} \vdash \neg \mathrm{B}:\|\neg \mathrm{B}\|=0,2 \cdot 0,4=$ $=0,05$.

Output step 2: $\neg \mathrm{A} 2, \neg \mathrm{A} 2 \rightarrow \neg \mathrm{B} \vdash \neg \mathrm{B}:\|\neg \mathrm{B}\|=0,1 \cdot 0,5=$

Output step 3: The resulting degree of certainty that an event will occur

$$
\neg \mathrm{B}:\|\neg \mathrm{B}\|=0,08+0,05-0,08 * 0,05=0,126 .
$$
$12.6 \%$

The deficit of security for all industrial safety measures is

Output step 4: "Industrial safety is ensured, the system of personnel protection GCO" $=1-0,126=0,884$ "excellent".

\section{CONCLUSION}

The methodology of logico-axiological estimation allows to build aggregated estimates of the state of the security system of GCO. The methodology is implemented on the basis of technology of expert systems and relies on NOT factors as the reason for the emergence of a risk situation, which is expressed in the reduction of the level of safety of the GCO.

\section{REFERENCES}

[1] K.W. Buiko, Yu.V. Pantyukhova "Approaches to assessing the level of industrial safety in organizations operating hazardous production facilities," Access mode: http://kalugatechnadzor.ru/analitika/371podxody-k-oczenke-urovnya-promyshlennoj-bezopasnosti-vorganizacziyax-ekspluatiruyushhix-opasnye-proizvodstvennye-obekty. (references)

[2] S.N. Kuznetsova "Methods of designing the mathematical support of systems for forecasting natural, technogenic and environmental risks": the author's abstract. dis. ... cand. tech. sciences. St. Petersburg, 2009, 20 p.

[3] A.A. Kuzmin, A.G. Chirikov "Approach to assessing the level of safety of hazardous production facilities using elements of the theory of qualimetry" in Scientific and educational problems of civil protection. 2010, №. 4, pp. 1-9.

[4] A. Veltri, M. Pagell, M. Behm, A. Das A Data"Based Evaluation of the Relationship between Occupational Safety and Operating Performance" in Journal of SH\&E Research, 2007, vol. 4, №. 1, pp. 1-22.

[5] L. Ateekh-ur-Rehman "Safety Management in a Manufacturing Company: Six Sigma Approach" in Engineering, 2012, №. 4, pp. 400407.

[6] A. Anvari, N. Zulkifli, R.M. Yusuff "Evaluation of Approaches to Safety in Lean Manufacturing and Safety Management Systems and Clarification of the Relationship Between Them" in World Applied Sciences Journal, 2011, 15 (1), pp. 19-26.

[7] I. Mohammadfam, M. Kamalinia, M. Momeni, R. Golmohammadi, Y. Hamidi, A. Soltanian "Evaluation of the Quality of Occupational Health and Safety Management Systems Based on Key Performance Indicators in Certified Organizations" in Safety and Health at Work, June 2017,vol. 8, pp. 156-161.

[8] L.V. Arshinsky "Logical-axiological approach to the assessment of the state of systems" in Modern technologies. System analysis. Modeling, 2013, №. 3 (39), pp.140-146.

[9] L.V. Arshinsky "Logical-axiological assessment of the qualitative state of the system" in Transport infrastructure of the Siberian region: Materials of the fourth All-Russian scientific and practical conference with international participation, May 13-17, 2013 Irkutsk: In 2 vol. Irkutsk: Izdatelstvo IrGUPS, 2013, vol. 1, pp.57-62.

[10] L.V. Arshinsky "The technique of the aggregated estimation of systems with support of key components" in Ontology of designing, 2015, vol. 5, № 2 (16), pp. 223-232.

[11] L.A. Arshinskiy, V.L. Arshinskiy, A.P. Khomenko S.K. Kargapol'tcev, B.P. Korol'kov, V.S. Aslamova Logical-mathematical modeling of complex subjecs vector semantics in Far East Journal of Mathematical Sciences, 2017, vol. 101, №r 4, pp. 813-823. 